\title{
Momentos Marcantes na Construção da Mudança em Terapia Familiar ${ }^{1}$
}

\author{
Emerson F. Rasera ${ }^{2}$ \\ Universidade Federal de Uberlândia \\ Carla Guanaes \\ Universidade de São Paulo (Ribeirão Preto)
}

\begin{abstract}
RESUMO - Assumindo as contribuições construcionistas sociais, esse estudo visa compreender o processo de produção de sentidos sobre a mudança em terapia familiar. Para isso, analisamos o processo terapêutico de uma família a partir da transcrição integral das sessões vídeo-gravadas. Baseado no método da poética social, buscamos identificar momentos marcantes do processo terapêutico vividos pelos terapeutas e familiares. Nossa análise apontou que a construção conversacional da mudança terapêutica foi marcada pelo deslocamento do discurso do problema individual para o da responsabilidade compartilhada, em que a definição do problema como algo individual foi desconstruída, passando o mesmo a ser considerado relacionalmente. Concluímos que o investimento dos terapeutas na construção de uma atmosfera dialógica e não-avaliativa foi fundamental para a emergência desses sentidos de mudança.
\end{abstract}

Palavras-chave: família; terapia familiar; estudo de caso.

\section{Arresting Moments in the Construction of Change in Family Therapy}

\begin{abstract}
Considering social constructionist contributions, this study intents to comprehend the meaning making process about change in family therapy. We analyzed the therapeutic process of a family based on the transcripts of video-taped sessions. Anchored in the social poetics practice, we aimed to identify some arresting moments of the therapeutic process lived by the therapists and the family members. Our analysis pointed out that the conversational construction of the therapeutic change was marked by the displacement from an individual problem discourse to one of shared responsibility, in which the definition of the problem as something individual was deconstructed and began to be done in more relational terms. We concluded that the therapists' efforts in the construction of a dialogic and non-judgmental atmosphere were fundamental for the emergence of meanings of change.
\end{abstract}

Keywords: family; family therapy; case study.

O estudo da mudança terapêutica é um dos temas mais valorizados em Psicologia Clínica. Diversos métodos têm sido utilizados na construção do conhecimento a respeito desse tema, desde modelos marcados por uma lógica quantitativa, pelo uso de questionários e escalas padronizados aplicados antes e após a intervenção com grupos experimentais e controle, com especial interesse pelos resultados da terapia, até aqueles influenciados por perspectivas qualitativas, constituídos por estudos de caso em profundidade e interessados no processo da terapia.

O foco no processo da mudança terapêutica, apesar de ter recebido olhares de suspeita da comunidade acadêmica (Beutler, 1990), tem ganhado novas contribuições, especialmente de pesquisadores preocupados com a utilidade do conhecimento científico para a prática clínica (Gale, Chenail, Watson, Wright \& Bell, 1996; Grandesso, 2009). Na terapia familiar, especificamente, as contribuições construcionistas têm promovido desenvolvimentos nesse campo, dado seus

1 Os autores agradecem aos participantes do estudo (membros da família e equipe terapêutica) pelas aprendizagens compartilhadas e à Profa. Dra. Marisa Japur pela leitura e sugestões.

2 Endereço para correspondência: Instituto de Psicologia, Universidade Federal de Uberlândia. Av. Pará, 1720, Bloco 2C. Uberlândia, MG. CEP 38400-902.E-mail: emersonrasera@uol.com.br. pressupostos epistemológicos e as posturas daí decorrentes para a prática clínica.

O construcionismo social está associado a um conjunto complexo de diferentes propostas teóricas nas ciências humanas que buscam, em uma perspectiva pós-moderna, enfatizar o caráter relacional e histórico de construção da realidade e o papel performático da linguagem nesse processo (Gergen, 1997; Shotter, 1998).

Na prática clínica, as terapias influenciadas pelo construcionismo também consistem um conjunto diversificado de abordagens, com teorias, métodos e inteligibilidades próprias (Grandesso, 2000; McNamee \& Gergen, 1990/1998). Entre essas propostas, destacam-se: a Abordagem Colaborativa (Anderson, 1997/2009), a Terapia Narrativa (White \& Epston, 1990) e os Processos Reflexivos (Andersen, 1991/1999).

Apesar da diversidade aí existente, podemos dizer que essas propostas, em diferentes graus, enfatizam uma postura do terapeuta marcada por: posição de coconstrução, foco no relacionamento, interesse pelo significado, ênfase polivocal, foco na ação e sensibilidade a valores. Comum a essas propostas é a tentativa de construção de uma prática clínica em que o foco na linguagem e nos processos relacionais é privilegiado (Rasera \& Japur, 2007).

De forma geral, podemos dizer que nessas propostas a mudança terapêutica está associada à construção de novas 
narrativas nas quais o senso de autoria dos clientes é resgatado. Abandona-se uma visão essencialista, classificatória e diagnóstica do problema e sua solução, pautada pelo saber a priori do terapeuta como especialista, e enfatizase a construção local de um conhecimento significativo para as pessoas envolvidas. A partir disso, enfatiza-se a importância e a utilidade de compreensão do processo terapêutico, mais do que uma descrição dos resultados obtidos na terapia.

Uma forma construcionista específica de se entender o processo de produção de sentidos de mudança na relação terapêutica é descrita por Shotter e Katz (1998) como poética social. Esses autores focalizam a compreensão das formas especiais de diálogo que se desenvolvem no contexto terapêutico, descrevendo alguns modos de fala e de interação que criam aberturas para a construção conversacional da mudança.

O termo poética social deriva do grego poesis, e significa dar forma a algo ou alguma coisa. Aplicando essa compreensão ao contexto terapêutico, Shotter e Katz (1998) entendem que alguns modos de fala e de interação terapeuta-cliente/ família criam a possibilidade para a emergência de novidade, de um sentido que vem dar forma a algo ainda vivido como sem possibilidade de expressão - geralmente relacionado ao problema que motivou a busca de terapia. Esse tipo especial de interação acontece em momentos significativos, usualmente vividos como marcantes por aqueles envolvidos. Compreender o que acontece nesses momentos é central para se descrever como sentidos únicos podem emergir na relação terapêutica, alterando as formas das pessoas se relacionarem consigo mesmas e com o mundo ao seu redor.

Para Shotter e Katz (1996), momentos marcantes ocorrem apenas em conversas dialógicas. Eles envolvem um tipo especial de conversação, em que as pessoas constroem uma forma de falar que é tanto relacional como responsiva. Nesse tipo de interação, as pessoas podem criar um entendimento compartilhado e legitimado sobre o que é importante para elas e, sobretudo por meio da construção de conexões entre os eventos narrados, podem pensar conjuntamente com o terapeuta e com os outros participantes da equipe terapêutica sobre soluções criativas para seus problemas.

Como ressalta Guanaes (2006), tais momentos marcantes, oriundos da prática da poética social e descritos pelas pessoas como centrais na mudança de situações-problema, não acontecem apenas na terapia, mas em todo relacionamento humano no qual uma interação dialógica permita a compreensão do outro em sua diferença e alteridade. A terapia destaca-se como um contexto privilegiado para esse tipo de interação dado o compromisso com a construção de um relacionamento menos hierárquico e avaliativo entre as pessoas, e por ser um tipo de conversa criativa que é, a priori, orientado pela busca por transformação ou mudança.

O objetivo deste estudo é compreender o processo de produção de sentidos sobre a mudança terapêutica construído no contexto de um atendimento em terapia familiar. Buscamos, especificamente, identificar momentos marcantes para terapeutas e familiares ocorridos ao longo das sessões e que contribuíram para a construção da narrativa sobre a mudança relatada.

\section{Método}

\section{Participantes}

Adotando as contribuições das perspectivas construcionistas sociais em terapia familiar e, especificamente, as contribuições de Andersen (1991/1999) sobre processos reflexivos, os atendimentos descritos neste estudo foram realizados por uma dupla de terapeutas de campo e por uma equipe reflexiva (dois terapeutas e um supervisor). Assim, participaram do atendimento:

A família: composta pelo pai Vagner (36 anos) e pela mãe Priscila (34 anos), casados há 12 anos, e pelos filhos Gustavo (11 anos), Thiago (7 anos) e Henrique (4 anos). Foi encaminhada para atendimento pela psicopedagoga que havia acompanhado Gustavo em suas dificuldades.

Terapeutas de campo 1 e 2 (T1 e T2): são psicólogos há 10 anos, professores universitários, terapeutas familiares, e autores deste estudo. Esses terapeutas realizaram o atendimento em dupla e foram responsáveis pelo atendimento da família.

Terapeutas da equipe reflexiva 3, 4 e 5 (T3, T4 e T5): duas terapeutas - uma psicóloga formada há quatro anos e uma assistente social com 27 anos de experiência - e uma supervisora - psiquiatra, terapeuta de casal e de família, com 35 anos de experiência.

A família consentiu em participar do atendimento na forma proposta (equipe reflexiva), em ter todas as sessões do atendimento gravadas em vídeo e em ter uma descrição do atendimento na forma de estudo de caso, a ser divulgado em revista científica. Este processo se concretizou, formalmente, com a assinatura do Termo de Consentimento Livre e Esclarecido.

\section{Ambiente}

$\mathrm{O}$ atendimento foi realizado em um instituto de terapia de família e casal, localizado no interior de São Paulo, que oferece atendimentos gratuitos, mensais e com uma hora de duração.

Este instituto adota o modelo de atendimento em "equipe reflexiva", proposto por Andersen (1991/1999). Trata-se de uma técnica conversacional em que os terapeutas de campo (dupla de terapeutas responsável pelo atendimento da família) contam com a participação de outros terapeutas (a equipe) que acompanham o atendimento através de um espelho unidirecional ou em um local delimitado da sala. No caso apresentado neste artigo, a equipe se manteve no lado oposto à família na sala de atendimento, sendo convidada a participar do diálogo com a família em determinados momentos. Quando a equipe é convidada a participar do diálogo, há uma troca de posições - ou seja, a família troca de lugar com a equipe e assume a posição de escuta, ouvindo o que a equipe conversa/reflete sobre as conversas até então desenvolvidas. Após esse momento, novamente há uma troca de lugares, quando a família e os terapeutas de campo passam a conversar sobre o que ouviram da equipe reflexiva. Esse processo pode ser repetido sempre que os terapeutas de campo julgarem necessário e útil para a ampliação do diálogo desenvolvido 
com a família. Essa técnica tem por objetivo ampliar as vozes presentes no diálogo, permitindo ao terapeuta e à família fazer escolhas entre os discursos que podem ser mais úteis na transformação das narrativas de problema.

\section{Procedimento}

A queixa inicial que motivou o atendimento se referia a dificuldades de relacionamento do filho mais velho, que vinha se comportando de modo agressivo, sobretudo com os irmãos. Nas palavras do pai na primeira sessão, "agora ele começou a ter briga com crianças, a dar um safanões neles, amoitar, coisas que ele não fazia". Além disso, os pais queixavam-se de que Gustavo estava mais desobediente, não aceitando as regras colocadas e ficando muito nervoso, o que antes não acontecia.

$\mathrm{O}$ atendimento se deu em cinco sessões realizadas no período de junho a novembro de 2006. As sessões transcorreram de forma tranquila e a família mostrou-se colaborativa e comprometida durante todo o atendimento.

A escolha do atendimento dessa família para análise se deveu a vários fatores: a família mostrou-se satisfeita com a mudança ocorrida, descrevendo claramente as aprendizagens do processo terapêutico; os terapeutas consideraram um atendimento exitoso, reconhecendo a transformação ocorrida em curto espaço de tempo; a mudança apresentada pela família ilustra claramente o caráter relacional da mesma.

\section{Análise de dados}

O corpus para análise foi constituído pela transcrição das cinco sessões de atendimento, as quais foram gravadas em videocassete e transcritas integralmente. As normas de transcrição foram inspiradas na proposta de Schiffrin (1999).

A análise desse material baseou-se nas propostas construcionistas de pesquisa em psicoterapia (Rasera \& Guanaes, 2006), na metodologia de estudo de caso (Stake, 2000) e especificamente na poética social como prática de investigação (Shotter, 1998; Cunliffe, 2002). O objetivo desse tipo de investigação é descrever os processos discursivos e relacionais de produção de sentidos, focalizando o modo como as pessoas constroem, numa ação conjunta e corporificada de uso da linguagem, determinadas realidades conversacionais. Aplicada à pesquisa, esse método destaca a importância de uma relação dialógica e envolvida do pesquisador com seu objeto de estudo, por meio da qual ele vem dar forma ou sentido aos momentos marcantes que capturam sua atenção, buscando construir relações ou conexões criativas entre esses e outros aspectos da vida social, assim ampliando a compreensão dos mesmos (Guanaes, 2006).

Em nosso estudo, a aplicação desse método de investigação voltou-se à: (a) identificação dos momentos marcantes no processo terapêutico, tal como descritos pela família; e (b) descrição de tais momentos marcantes, buscando a compreensão dos processos dialógicos a partir dos quais a terapia emergiu como um contexto de mudança. A partir desse processo de análise, chegamos aos resultados relatados a seguir.

\section{Resultados}

Para apresentação de nossos resultados, tomamos como eixo a última sessão de terapia, em que a família fez comentários sobre o processo terapêutico, avaliando-o positivamente e descrevendo seus "momentos marcantes". Esses resultados mostram um mudança de perspectiva do problema individual para a responsabilidade compartilhada.

Também consideramos como eixo na apresentação dos resultados a descrição de um importante processo conversacional que marca a mudança terapêutica dessa família, e que descrevemos como o deslocamento do discurso do problema individual para o discurso da "responsabilidade compartilhada". Entendemos por "responsabilidade compartilhada" uma perspectiva conversacional em que o problema passa a ser descrito em termos relacionais, de modo que sua solução passa a ser pensada também como uma busca coletiva e corresponsável (McNamee \& Gergen, 1990/1998). Nesse atendimento específico, tal processo de construção foi analisado em relação a três aspectos centrais, descritos a seguir: (a) a definição do problema como não sendo apenas de um dos filhos, mas de toda família; (b) a construção das soluções do problema como sendo também da família, e não apenas da equipe terapêutica; e (c) as mudanças como pais e casal.

\section{A definição do problema como não sendo de um dos filhos, mas de toda a família}

Alguns momentos marcantes no processo da terapia com esta família se articularam em torno do deslocamento do discurso do problema inicial como sendo de um dos filhos, para uma descrição mais relacional, que envolvia a compreensão da participação de toda a família na sustentação do problema. Esses momentos apontavam para uma redefinição dos membros da família, suas capacidades e dificuldades. Destacamos, a seguir, alguns momentos em que vimos essa mudança ocorrendo.

No contexto da sessão final, Priscila e Vagner afirmaram que quando procuraram a terapia, achavam que o problema era apenas com o Gustavo, pois este vinha se comportando de modo agressivo, envolvendo-se frequentemente em brigas com os irmãos. Ao longo da terapia, perceberam que todos tinham dificuldades e tinham que mudar. Apresentaremos, a seguir, trechos das sessões que ilustram esse processo conversacional.

Na terceira sessão, os terapeutas propõem que a família trabalhe conjuntamente para a realização de um desenho sobre "a casa da família". Eles aceitam a tarefa e, após o término, os terapeutas conversam com a família sobre os desenhos. Durante a atividade, alguns aspectos nos chamaram a atenção: Thiago tomou a frente do desenho e Gustavo cedeu espaço ao irmão; ocorreu uma situação em que Henrique se desentendeu com Gustavo, e iniciou um comportamento de birra, afastando-se e demorando a voltar a participar. Essa situação, além das conversas sobre o desenho, permitiu algumas reflexões: a participação ativa de Thiago; o fato de Gustavo, como filho mais velho, ceder espaço aos mais novos; e a identificação de que Henrique, assim como Thiago e Gustavo, também fica 'nervoso'. Na sessão, durante a ex- 
ploração sobre o desenho, as crianças contam como brigam e ficam nervosas, em uma narrativa que contrasta com o que ocorreu durante a realização da atividade. Os terapeutas buscam compreender a situação.

T1: Eu achei engraçado, porque vocês estão falando do Gustavo que ficou nervoso, né? Mas aqui, na hora que a gente tava desenhando, na hora que o Gustavo foi desenhar, ai quem ficou chateado, quem ficou nervoso foi o Henrique... Isso acontece também, de às vezes quem fica nervoso ser o Henrique e não o Gustavo, ou você acha que é sempre o Gustavo que fica nervoso?

Thiago: Os três ficam nervoso. (...)

T1: Gustavo, vocêficou nervoso com o Henrique na hora do desenho?

Gustavo: Não.

Thiago: Eu sei porque.

T1 (para Gustavo): Não ficou... Por que você não ficou? O que você acha que aconteceu que você não ficou nervoso na hora que tava desenhando?

Gustavo: Porque não pode bater nele, que ele é pequenininho (?).

Thiago: Eu sei porque ele não ficou nervoso. Porque meu pai está aqui. E quando meu pai e minha mãe tá aqui ele tem medo que bate nele. (...)

T2: E o Vagner, o que você pensa quando ouve o Thiago falar essas coisas?

Vagner: Na realidade, no momento você acha que... que criança passa despercebido, que não presta atenção e você vê aqui que não, que eles estão prestando atenção. Agora, por exemplo, ele falou porque eles não ficavam muito perto... Porque assim... isso ele nunca falou!

Nesse momento, é interessante notar como a observação do terapeuta fez sentido para as crianças, apontando que havia uma maneira típica na família de descrever Gustavo como nervoso, mas que se referia a um comportamento comum a todos os filhos. Além disso, ao se conversar sobre quando e como Gustavo fica nervoso, o caráter relacional desse comportamento é explicitado, e aparecem as implicações de reagir frente às ações do Henrique. Vagner se surpreende com as colocações do filho, sensibilizando-se e redimensionado sua percepção da situação.

A equipe reflexiva é chamada a contribuir com o diálogo, e uma das terapeutas (T5) aponta o quanto é comum nas famílias que os filhos mais velhos sejam cobrados de dar espaço aos mais novos. Essa fala é retomada por um dos terapeutas de campo (T1) na conversa posterior com a família, buscando ampliar a discussão sobre o assunto. $\mathrm{O}$ trecho abaixo selecionado sintetiza o processo acima descrito de construção de novas posições na descrição do problema:

T1: Uma coisa que a (T5) falou e que me trouxe uma impressão que eu quero dividir com vocês pra ver o que vocês acham. (...) Eu observei que várias vezes, no desenho, o Gustavo fazia um movimento e ele deixava os meninos fazerem no lugar dele, ou cedia espaço, passava a vez... Até agora na hora de falar, eu fiz uma pergunta pro Gustavo e o Thiago respondeu.... E eu queria ouvir um pouco a opinião de vocês sobre isso, se o Gustavo tem esse lugar, né, de filho mais velho que passa a vez, que deixa os mais novos fazerem e de como é que vocês acham que ele sente isso, de estar dando o lugar, de deixar os mais novos ocuparem um pouco mais desse espaço. Não sei se vocês também têm essa observação... (...)

Priscila: Essa questão de espaço mesmo, os meninos mais novos acabam abusando disso e querendo mais atenção da gente, querendo falar mais e a gente acaba... (...) Eu acho que... Eu não sei, talvez essa coisa de bater nos irmãos talvez seja uma forma de descontar o que ele tá sentindo... que os irmãos acabam tomando lugar, que ocupam o lugar... (...)

Vagner: Eu senti que o Gustavo, ele sempre foi uma criança fácil de lidar. A partir do momento que começou a aparecer os meninos ele ficou mais dificil (...) As vezes que acontece dele brigar, o que a gente está prestando atenção é isso. Às vezes ele não tem espaço, os dois não dão e ele acaba batendo... (...) E tem outra coisa que a gente tá percebendo, que é que o Henrique (...), é que ele fica se fazendo de bonzinho, mas na verdade ele é o causador de briga. (...)

Nesse momento, os pais conversam entre si, transformando a visão sobre as posições ocupadas pelos filhos na construção do problema. Caminham, assim, em direção a uma compreensão mais relacional e flexível sobre a problemática inicialmente apresentada, que permite novas posições para todos os envolvidos.

Nessa conversa, é possível observar uma transformação nas descrições sobre Gustavo. Ele deixa de ser descrito como a fonte dos problemas, tendo suas necessidades e as consequências de ser filho mais velho destacadas. Nesse processo, explora-se também uma explicação relacional para as ações de Gustavo, na qual todos os membros da família estão implicados. Essa conversa permite a flexibilização nas descrições sobre os filhos, havendo uma contextualização que amplia a forma de entendimento das situações vividas pela família e exige novas descrições de seus membros.

\section{A construção das soluções do problema como sendo também da família, e não apenas da equipe terapêutica}

Outro aspecto que destacamos em nossa análise diz respeito à mudança no modo como a família passou a descrever a solução do problema apresentado aos terapeutas. Enquanto, inicialmente, havia por parte da família uma expectativa de que os terapeutas apresentassem a solução para suas dificuldades, ao fim dos atendimentos a família passou a perceber seus recursos para construir caminhos em busca da solução. Descrevemos, a seguir, momentos marcantes desse processo.

Avaliando o processo terapêutico, na última sessão, Priscila e Vagner descrevem momentos vividos na relação com os terapeutas e equipe reflexiva, a partir dos quais puderam resgatar um maior senso de controle sobre sua vida. Relatam ainda, terem desenvolvido um maior senso de autoria na construção de possibilidades de mudança e, desse modo, também uma maior autonomia sobre as decisões tomadas no cotidiano da família. Nessa situação, Priscila e Vagner descrevem que foi importante perceber que quando levavam questões para serem discutidas na terapia familiar, os terapeutas evitavam dar a resposta sobre como deveriam agir, levando-os a 
refletir sobre sua compreensão sobre o problema. Ficaram marcados com esse modo de conversar, que os fez perceber que a capacidade para decidir sobre o caminho a seguir era da própria família, e não da equipe.

Frente a esse sentido de mudança trazido pelo casal, selecionamos momentos da quarta sessão que nos marcaram como terapeutas e que ilustram esse processo de mudança vivido pela família, em direção a um maior senso de agenciamento. Nessa sessão, Priscila coloca dúvidas em relação à educação das crianças. Descreve uma situação em que Gustavo não fez a lição de escola e falsificou sua assinatura. Priscila queixa-se também sobre o comportamento de Thiago, que chora sempre que leva um "não", sobretudo em relação ao jogo de videogame. Diz que não sabe se está certa ao adotar algumas posturas em relação ao tempo que as crianças gastam jogando. Priscila coloca suas dúvidas e, frente a elas, os terapeutas investigam o que eles normalmente fazem para lidar com tais situações.

Priscila e Vagner contam, então, sobre suas infâncias e sobre como agiam quando crianças. Contam dos acordos que faziam, de suas relações com os irmãos e de como agiam para convencer seus pais ou responsáveis de alterarem as regras. Surge, a partir desse diálogo, o sentido de que as crianças sempre tentam mudar os limites para conseguir realizar seus desejos. Após essa conversa, a equipe reflexiva é chamada para participar do diálogo. A família e os terapeutas assumem a posição de escuta. $\mathrm{Na}$ fala da equipe reflexiva, a legitimação dos lugares de pai e mãe pelos filhos é ressaltada, construindo as posições de pais cuidadosos e de filhos obedientes. Além disso, questionamentos são apresentados, levando a novas aberturas conversacionais:

T3: A gente estava escutando eles conversando, e eu percebi os pais muito cuidadosos na educação dos filhos e prestando muita atenção em como educar, se percebendo nessa tarefa. E eu ouvi, quando a Priscila pediu para o Thiago vir sentar, que ela queria conversar com ele junto, ela olhar para o marido. E eu não sei o que ela queria com esse olhar, se era que ele pedisse para o Thiago vir... E eles estavam conversando sobre como construir os limites, então eu queria saber como eles constroem o que as crianças podem ou não fazer. Acho que é isso.

T5: Eu estou achando a conversa muito interessante, $e$ me passou muitas coisas pela cabeça, (...)Então eu fiquei pensando um pouco... do que eles contaram do Gustavo, do que eles contaram do Thiago... e me veio um pouco na cabeça a palavra crença. De que como é que... Como é que eles poderiam se dar conta de que talvez eles precisavam estar se acreditando mais uns nos outros. Pensar na crença de que tem algo muito bom. (...) Eu queria reforçar a palavra crença, crença no sentido de crédito. No que um acredita nos outros, deles poderem acreditar uns nos outros...

Trocando os lugares com a equipe reflexiva, os terapeutas retomam o diálogo com a família, pedindo para que conversem sobre o que ouviram. Priscila fala, então, de seu desejo de dividir responsabilidades com Vagner. Diz do que significa para ela ter três filhos para cuidar, do quanto se sente sobrecarregada e da responsabilidade de ter que decidir por três vidas. Pedidos podem ser feitos, criando possibilidades para novos padrões de ação dentro da família.

Notamos que nesse processo conversacional acontece o deslocamento de um conteúdo inicial prescritivo (Deve-se ou não deixar os filhos jogarem videogame? Como colocar limites?) para uma reflexão criativa e dialógica sobre o processo de educação dos filhos, a influência de suas histórias pessoais na concepção do que é certo e errado, e sobre como o casal divide responsabilidades nesse processo. A palavra "crença" usada pela equipe reflexiva sintetiza a necessidade do casal dividir responsabilidades e de se apoiar nas decisões tomadas em relação à educação dos filhos. Aqui, a possibilidade de emergência de um maior senso de agenciamento aparece como resultado da explicitação e legitimação das ações tomadas no cotidiano da família; da divisão das dúvidas e incertezas que faziam parte dos processos de tomada de decisão; e da construção de um espaço seguro e não avaliativo para o casal construir pedidos de união e corresponsabilidade, revisitando suas histórias pessoais e revendo suas crenças.

Ao fim dessa sessão, avaliando algumas transformações feitas, Vagner e Priscila explicitam como têm conseguido alterar o padrão de tomada de decisões na família:

T2: E eu estou lembrando da primeira sessão de vocês aqui, da motivação para a terapia, que era a preocupação com a educação dos filhos, de um problema que havia acontecido anteriormente com o Gustavo... E as coisas mudaram um pouco (...). Eu queria saber, entre a primeira sessão e hoje, como é que vocês avaliam, qual é o sentimento de vocês em relação a essas questões que preocupavam vocês na educação deles...

Priscila: Eu acho que teve um grande avanço em relação a gente, das coisas que eles falaram, e deles também. Eu acho que o bloqueio era maior... Hoje a gente consegue conversar, consegue se comunicar numa boa. Eu vejo assim muita melhora. Que nem, na situação do Gustavo, se fosse antes, que ela ligou e falou, eu já tinha batido muito nele, e eu não fiz. Eu falei só pra ele que ele me deixou chateada, conversei com ele. Nesses momentos, a gente está mais conversando...

T2: E o Vagner?

Vagner: Eu acredito assim, que a partir do momento que a gente começou a fazer esses encontros, essas conversas... de voltar o inverso. Que toda vez, vocês falam como vocêé, como você agia?. (...) Tudo o que acontece hoje, nós fazíamos atrás, e às vezes a gente não quer entender... e não para pra pensar, a gente acha que a gente sempre foi grande, que nasceu assim perfeito... E dá pra gente refletir mais.

Percebemos, aqui, que o casal tem um aprendizado relativo ao próprio processo conversacional, mais do que ao conteúdo do que se conversa. A fala de Vagner mostra que ele começou a aplicar em seu cotidiano o mesmo movimento feito pelos terapeutas na sessão quando, resgatando as histórias pessoais, esses buscavam construir um caminho para ação valorizado e coerente com os valores da família.

Esse processo reflete o que Grandesso (2000) aponta em relação ao aprendizado derivado do processo terapêutico. Segundo a autora, o que os clientes geralmente levam consigo ao fim de uma terapia de base conversacional é 
a própria "compreensão de que os significados dependem dos contextos" (p.295), o que propicia, também, uma postura de maior flexibilidade diante da vida e dos relacionamentos.

\section{Mudanças como pais e como casal}

Por fim, em consonância com o processo de deslocamento de um discurso do problema individual para um discurso da responsabilidade compartilhada, a mudança desta família a partir da terapia implicou transformações na descrição de Priscila e Vagner como pais e como casal. É a construção dessa mudança no processo conversacional da terapia que descreveremos a seguir.

No contexto da sessão final, Priscila e Vagner relatam algumas mudanças em decorrência da participação na terapia: começaram a dividir responsabilidades, a partir da consciência de que cada um poderia agir diferente; Priscila passou a se sentir mais respeitada por Vagner, ao mesmo tempo em que também passou a confiar mais nele; ela começou a legitimar as ordens que ele dava e Vagner passou a defendê-la espontaneamente na relação com os filhos; Vagner começou a resolver os problemas no momento em que ocorriam, sem postergá-los como antes fazia; e Priscila parou de criticá-lo, apoiando mais seus planos e ações.

Durante a quarta sessão, há um momento marcante relacionado ao processo de mudança de Priscila e Vagner como pais e como casal. Como descrevemos em um dos trechos já apresentados, nessa quarta sessão, a equipe reflexiva aponta a importância de darem mais crédito uns aos outros. Os pais relatam, então, o receio de darem crédito aos filhos e perderem o controle da situação. Contudo, a possibilidade de dar crédito não diz respeito apenas aos filhos, mas também perpassa a relação dos dois como casal.

Priscila: Uma outra coisa que eu lembrei, da moça que tava sentada aqui, é que ela falou que eu olhei pra ele na hora que eu pedi pro Thiago sentar, e que ela não sabia o que eu queria dizer. O que eu queria era dizer pro Vagner pedir pra ele sentar. Porque eu sinto que ele tinha que ser mais enérgico com eles, e quem é sou eu. E isso me afasta deles, e eu espero isso do Vagner, que ele seja mais enérgico, que ele não é.

T2: Isso é uma coisa que nesse período mudou um pouco ou não?

Vagner: Não. Ela sempre me culpou.

T2: Como que vocês acham que podem fazer essa divisão aí...

Priscila: É exatamente, é uma divisão, eu acho que é uma divisão que está feita, e eu acho que tinha que ter outra divisão que não me deixasse com a sobrecarga.

Nesse momento, a partir do recorte de um comentário da equipe, Priscila situa sua insatisfação na forma como distribuem as responsabilidades na educação dos filhos. Contudo, Vagner não concorda com a forma como Priscila descreve o processo de construção da divisão das responsabilidades entre eles e novas negociações de sentido são feitas a partir da intervenção dos terapeutas:
T1: Priscila, se nessa situação da cadeira, que a T3 apontou... que você olhou pra ele desejando que ele pedisse para o Thiago sentar. Se o Vagner respondesse, 'ah, deixa ele brincar', pra você seria suficiente, ou o olhar era pedindo que ele dissesse a mesma coisa?

Priscila: Seria suficiente, ao menos seria uma reação, alguma coisa... Porque tudo, tudo 'sua mãe decide', 'sua mãe decide’. (...) E essa questão de decisões. Porque ele joga pra mim, porque ele não pode decidir?

Vagner: Um parênteses. (...) Isso acontece hoje, porque antigamente eu que tomava as decisões. Ai ela falava "Por que você falou sem me consultar? Mas porque você deixou?" (...) A partir daquele dia eu falei, eu não vou falar mais nada, você se vira. Então, a partir daquele momento, eu não falo mais nada, eu passo pra ela. (...)

Nesse trecho, a fala de Vagner traz o contexto de construção de algumas pautas de relacionamento entre o casal no passado. Seu comportamento de não auxiliar na tomada de decisões foi tomado a partir de negociações anteriores, feitas com Priscila, em outro momento do relacionamento do casal. A partir dessa descrição, o sentido de dar crédito um ao outro é retomado no diálogo, se abrindo para novas descrições.

T2: Tem uma coisa nessa história que a gente conversou um pouco, de dar crédito, de vocês em relação aos meninos. Mas não é só de vocês em relação a eles... É também de um em relação ao outro, e de vocês dois, entre vocês. (...)

Priscila: Na verdade, então, a gente não consegue dar crédito pra eles, porque a gente não tem...

Vagner: Não, eu dou crédito pra ela, não sei se ela não percebeu ainda. Se ela toma uma ação, eu tô prestando atenção, quando você exagera, eu falo com você.

T1: Olha que interessante, o que tá acontecendo agora, né? Que o Vagner tá dizendo que se ele fica em silêncio é porque ele tá apoiando a sua decisão. Você tinha essa visão, de que quando ele não fala é uma ação de apoiar, de legitimar o que você está fazendo?

Priscila: Não...

Terapeuta 1: E como é ouvir isso, Priscila...

Priscila: É muito bom saber isso, mas mesmo assim eu gostaria de dividir... porque é muita responsabilidade, e às vezes eu fico insegura... (...) E muito bom ouvir isso, porque raramente ele fala as coisas... mas mesmo assim, só comigo não é legal.

Opondo-se à visão apresentada por Priscila sobre a falta de crédito entre o casal, a fala de Vagner abre uma nova possibilidade de significação das ações. Aqui, o silêncio não significa abandono ou descaso, mas apoio e respeito pela decisão por ela tomada. Esse sentido é reiterado pelo terapeuta (T1) que, assinalando essa diferença, marca uma distinção que tem possíveis implicações para a transformação nas descrições pessoais desse casal. A conversa em torno da diversidade de significados abre a possibilidade para que Priscila explicite alguns pedidos para Vagner, assim permitindo a renegociação de antigos contratos. Vagner participa ativamente desse diálogo, também conseguindo colocar suas dificuldades em relação aos novos acordos. Nesse diálogo, as possibilidades de mudança são tomadas em processo. $\mathrm{O}$ casal está em diálogo, sensível à diversidade de valores e 
enfrentando o desafio de encontrar formas mais colaborativas de educação dos filhos.

As conversas dessa sessão parecem ter tido um efeito significativo no processo de mudança dessa família. É possível perceber o compromisso do casal na construção de uma nova forma de lidar com os filhos, em um exercício que os convida e exige que respondam não apenas como pais, mas como pessoas que têm uma história e uma potencialidade. Criou-se na sessão um espaço de abertura significativa para a construção de outras formas de se relacionarem em família.

\section{Considerações Finais}

$\mathrm{Na}$ maioria das perspectivas modernas em Psicologia, a mudança terapêutica é pensada de um modo linear, podendo ser avaliada e determinada por meio de evidências clínicas, tais como diagnósticos, comportamentos, sinais, sintomas etc. Entende-se que, por meio da terapia, a pessoa pode mudar ou transformar-se, seja evoluindo em termos de seu desenvolvimento psíquico ou emocional, seja transformando comportamentos problemáticos, seja, ainda, adquirindo um maior conhecimento de si mesma.

Em uma terapia orientada pelas reflexões construcionistas, a avaliação da mudança terapêutica não supõe uma trajetória linear, na qual a pessoa caminha de um "estágio" a outro, referido como melhor ou mais evoluído. Afinal, a própria descrição construcionista acerca dos processos de construção de si questiona a possibilidade de um conhecimento do "si mesmo" e de um discurso de si singular. Em decorrência disso, importa às terapias com foco na conversação, buscar os sentidos de mudança que mais se aproximem da narrativa de problema apresentada pelo cliente, e que possam ampliar suas possibilidades de vida e de relacionamento (Guanaes, 2006).

Metodologicamente, a utilização da poética social permitiu o entendimento da mudança como um processo descontínuo, no qual a ideia de "momento marcante" funciona como uma metáfora explicativa do processo de produção de sentidos, ressaltando o caráter relacional do mesmo. Essa forma de compreender a prática da poética social nos permite, ao mesmo tempo, descrever os momentos de grande transformação de sentidos no contexto psicoterápico, bem como, aquelas mudanças cotidianas construídas nas conversas entre as pessoas.

Concordamos com Grandesso (2000) que, para que haja a possibilidade de reconstrução de significados, é necessário que haja acontecimentos de quebra de sentido, de não encaixe, nos quais narrativas até então não questionadas passam a ser olhadas com estranhamento. Do mesmo modo, discutindo as possibilidades de significação que emergem a partir da prática da poética social, Shotter e Katz (1998) concluem que o objetivo de uma terapia de base conversacional é favorecer um entendimento que dá visibilidade a algo já presente no relato do cliente, mas que ainda não tinha se destacado como descrição predominante ou encontrado um espaço de participação em outras conversas:

Os problemas humanos em psicoterapia não são respondidos adicionando novos pedaços de informação para explicá-los ou solucioná-los. Eles são resolvidos com o terapeuta ajudando seus clientes a criarem novos modos de 'seguir'em suas vidas ao interconectarem e relacionarem velhos fatos de novas maneiras. (p. 82)

Nas sessões com a família, buscamos construir uma atmosfera dialógica propícia à desconstrução das narrativas que reificavam posições estáticas para a família. A mudança nas descrições do casal sobre o problema que motivou a busca da terapia, sobre as crianças e as brigas, e sobre a divisão de responsabilidades, entre outras, resultou do investimento dos terapeutas e da equipe reflexiva na construção de uma atmosfera relacional não avaliativa e respeitosa, na qual descrições alternativas pudessem ser acolhidas e trazidas à reflexão. Assim, novas conexões entre velhos fatos eram construídas pela família, possibilitando a criação conversacional de novas realidades.

Em nossa análise, percebemos que a família viveu como marcante o entendimento de que, para além do conteúdo discutido, havia um determinado processo conversacional em desenvolvimento. Esse processo era marcado por perguntas, questionamentos, reflexões, escuta, não-julgamento, curiosidade, observação. Um processo em que histórias presentes e passadas eram revisitadas, descritas e redescritas a partir de diferentes pontos de vista - tantos quanto dos diferentes atores envolvidos. Levaram, assim, como aprendizagem, a compreensão sobre um modo de conversar e se relacionar, útil para construção de novos modos de ação e relacionamento familiar, também em outros contextos de suas vidas.

\section{Referências}

Andersen, T. (1999). Processos reflexivos (R. M. Bergallo, Trad.). Rio de Janeiro: Instituto Noos / ITF. (Trabalho original publicado em 1991)

Anderson, H. (2009). Conversação, linguagem e possibilidades (M. G. Armando, Trad.). São Paulo: Ed. Roca. (Trabalho original publicado em 1997)

Beutler, L. E. (1990). Introduction to the special series on advances in psychotherapy process research. Journal of Consulting and Clinical Psychology, 58, 263-264.

Cunlifee, A. L. (2002). Social poetics as management inquiry: A dialogical approach. Journal of Management Inquiry, 11,128-146.

Gale, J., Chenail, R., Watson, W., Wright, L., \& Bell, J. (1996). Research and practice: a reflexive and recursive relationship - three narratives, five voices. Marriage \& Family Review, 24, 275-295.

Gergen, K. J. (1997). Realities and relationships: Soundings in social construction. Cambridge: Harvard University.

Grandesso, M. (2000). Sobre a reconstrução do significado: uma análise epistemológica e hermenêutica da prática clínica. São Paulo: Casa do Psicólogo.

Grandesso, M. (2009). Desenvolvimentos em terapia familiar: das teorias às práticas e das práticas às teorias. Em L. C. Osório \& M. E. P. Valle (Org.), Manual de terapia familiar (pp. 104-118). Porto Alegre: ArtMed.

Guanaes, C. (2006). A construção da mudança em terapia de grupo: um enfoque construcionista social. São Paulo: Vetor.

McNamee, S., \& Gergen, K. (1998). A terapia como construção social (C. O. Dornelles, Trad). Porto Alegre: Artes Médicas. (Trabalho original publicado em 1990) 
Rasera, E. F., \& Guanaes, C. (2006). O terapeuta como produtor de conhecimentos: contribuições da perspectiva construcionista social. Nova Perspectiva Sistêmica, 26, 76-85.

Rasera, E. F., \& Japur, M. (2007). Grupo como construção social: aproximações entre o construcionismo social e a terapia de grupo. São Paulo: Vetor. .

Stake, R. E. (2000). Case studies. Em N. K. Denzin \& Y. S. Lincoln (Eds.), Handbook of qualitative research (pp. 435-454). London: Sage.

Schiffrin, C. (1998). Approaches to discourse. Cambridge: Blackwell.

Shotter, J. (1998). Social constructionism and social poetics: Oliver Sacks and the case of Dr. P. Em B. M. Bayer \& J. Shotter (Eds.), Reconstructing the psychological subject: Bodies, practices and technologies (pp. 33-51). London: Sage.
Shotter, J., \& Katz, A. M. (1996). Articulating a practice from within the practice itself: Establishing formative dialogues by the use of a "social poetics". Concepts and Transformation, 1, 213-237.

Shotter, J., \& Katz, A. M. (1998). 'Living moments' in dialogical exchanges. Human Systems, 9, 81-93.

White, M., \& Epston, D. (1990). Medios narrativos para fines terapéuticos. Buenos Aires: Paidós.

Recebido em 20.02.2008

Primeira decisão editorial em 25.03.2009

Versão final em 06.05.2009

Aceito em 14.07.2009 